\title{
Análisis de los diarios digitales españoles más influyentes y su presencia en las redes sociales
}

\author{
$\mathrm{M}^{\mathrm{a}}$ Mercedes ZAMARRA LÓPEZ \\ Universidad Complutense de Madrid \\ mzamarra@ucm.es
}

Recibido: 16 de julio de 2015

Aceptado: 18 de septiembre de 2015

\begin{abstract}
Resumen
Las redes sociales han trastocado radicalmente el panorama mediático y se han convertido en herramientas de comunicación humana y social con una gran relevancia en la sociedad actual. Las empresas, los seres humanos y los medios de comunicación las emplea con el objetivo de influir en un mayor número de personas, desde cualquier parte del planeta y en cualquier momento. Los grandes medios de comunicación han tenido que adaptarse a este nuevo periodismo 2.0 y los propios usuarios han adquirido el papel de transmisores de la información en tiempo real. Por ello, este trabajo tiene como objeto de estudio la relación existente entre los cuatros medios de comunicación españoles más importantes y las redes sociales, así como también la interacción efectiva que proporcionan a través de sus periodistas.

Palabras clave: Redes sociales, Twitter, seguidores, periodistas, periódicos.
\end{abstract}

\section{Analysis of the most influential Spanish digital newspapers and their presence on social networks}

\begin{abstract}
Social networks have radically change the media landscape and have become tools of human and social communication with a great relevance in today's society. Enterprises, humans and the media uses them aiming to influence a greater number of people, from anywhere in the world and any time. The large media have had to adapt to this new journalism 2.0 and the users themselves have taken on the role of transmitters of information in real time. Therefore, this piece of work aims to study the relationship between the four spanish media major and social networks, as well as the effective interaction provided by its journalists.
\end{abstract}

Keywords: Social networks, Twitter, followers, journalists, newspapers.

\section{Referencia normalizada}

ZAMARRA LÓPEZ, $M^{a}$ Mercedes (2015): “Análisis de los diarios digitales españoles más influyentes y su presencia en las redes sociales". Estudios sobre el Mensaje Periodístico. Núm. especial diciembre, págs.: 155-170. Madrid, Servicio de Publicaciones de la Universidad Complutense.

Sumario: 1. Introducción. 2. Objeto de estudio y metodología. 3. Medios impresos en la era digital; 3.1. Análisis de los medios en las redes sociales. 4. Análisis de los principales periodistas sociales en Twitter; 4.1. El País; 4.1.1. Miguel Ángel Bastenier: @MABastenier; 4.1.2. Carlos E. Cué: @carlosecue; 4.1.3. Fernando Garea: @Fgarea; 4.2.El Mundo; 4.2.1. Casimiro García Abadillo: @garcia_abadillo; 4.2.2. Fernando Lázaro Fernández: @lazaroelmundo; 4.2.3. Jaime Rodríguez Carrasco: @jaimeELMUNDO; 4.3.ABC; 4.3.1. Carlos Herrera Crusset: @carlosherreracr; 4.3.2. Hermann Tertsch: @hermanntertsch; 4.3.3. Bieito Rubido: @bieitorubido; 4.4. La Razón; 4.4.1. Francisco Marhuenda: @pacomarhuenda. 5. Conclusiones. 6. Referencias bibliográficas.

\section{Introducción}

La llegada de la era digital y con ella, las nuevas tecnologías, ha generado un crecimiento tecnológico sin precedentes, que ha supuesto, un profundo cambio en la forma de proceder, entender y relacionarse con el mundo, por parte de los países, las empresas, los medios de comunicación y las personas. Así estas nuevas tecnologías ini- 
ciaron la transición hacia la sociedad de la información o del conocimiento en la que vivimos actualmente (Campos, 2008: web). Las nuevas tecnologías han condicionado la creación de nuevas técnicas y elementos, que han ampliado exponencialmente, los medios y capacidades de la comunicación humana, esto ha influido de forma muy notable en el periodismo y la transmisión de información.

Esta transformación, aunque pueda no parecerlo, ha hecho que la mayoría de los hábitos de la sociedad cambiasen en muy poco tiempo. El motivo de esta nueva concepción de la realidad, se debe en gran medida al constante flujo de información al que estamos sometidos: la instantaneidad que proporciona la Red, las constantes actualizaciones de la información... son sólo algunas de las características que han conseguido poco a poco transformar las antiguas pautas sociales. Pero sin duda, la característica más sorprendente que ofrecen las redes sociales, es la posibilidad de que los usuarios puedan responder ante la información que se les presenta (Requejo, 2012: 153). Esta novedad consigue que los receptores puedan dar su opinión, aportar información adicional, debatir en foros... que la comunicación adquiera una nueva fórmula mucho más dinámica (Flores, 2013: 148).

La omnipresente utilización de las redes sociales ha producido numerosas transformaciones de gran calado. Los usuarios de estos nuevos medios establecen constantes relaciones entre sí, haciendo que el concepto de globalización adquiera unas dimensiones insospechables hace tan sólo unos años. Esto se debe, entre otras cosas, a la enorme capacidad de concentración de masas que caracteriza a los medios digitales y al esfuerzo que estos medios realizan para cuidar y tener en cuenta el nexo de unión con sus lectores.

\section{Objeto de estudio y metodología}

Las redes sociales han abierto posibilidades que antiguamente se hubiesen considerado una utopía. El contacto directo con las fuentes, la posibilidad de recibir comentarios al instante por parte del público y la oportunidad de conocer lo que está sucediendo en tiempo real en cualquier parte del mundo, son solo algunos aspectos de una revolución que influye diariamente la labor periodística. Internet, y las redes sociales en particular, han modificado los pilares clásicos en los que se sustentaban los tradicionales sistemas y modelos de comunicación (Cebrián, 2010: 65).

La fuerza que han adquirido hoy en día redes sociales ha provocado, una mayor involucración por parte de los medios de comunicación en estas, con el fin de mejorar sus contenidos y productos en un mundo digital, cada día más competitivo y donde dar una primicia o actualizar una noticia e información, un minuto antes o después, puede suponer el reconocimiento nacional o mundial de una sociedad que puede acceder, demandar e incluso ofrecer información continua las 24 horas del día en cualquier parte del planeta. Los medios, han visto aumentada de forma abrumadora su influencia en la sociedad, donde ahora un solo medio puede ofrecer no sólo noticias, sino cualquier otro tipo de información especializada, fotografías, infografías, vídeos, audios.

Para realizar el análisis de la repercusión de las cuentas asociadas a periódicos y periodistas en las redes sociales hemos decidido, atenernos e investigar la red social Twitter como ejemplo específico, puesto que es la red social donde se puede encontrar presentes el mayor número representativo de los medios, y son las cuentas más 
personales y utilizadas por la mayoría de ellos, lo que nos proporciona una muestra más real de su repercusión y del uso que hacen de las mismas. Por ello antes introduciremos una breve aclaratoria, sobre el concepto y la función de Twitter.

Twitter es una red social bajo el concepto de microblogging, es decir, los usuarios registrados pueden publicar sus comentarios o tuits de una forma breve, únicamente pueden usar 140 caracteres, los cuáles pueden ser empleados también para publicar enlaces a otros sitios web, en los que podemos encontrar contenidos más amplios.

Su éxito reside en la brevedad y rapidez con la que se publican los mensajes, la posibilidad de alcanzar al instante al testigo en el lugar de los hechos (García de Torres et al., 2011: 618). Esto aporta instantaneidad a los medios de comunicación, aparte de la gran capacidad de movilización y difusión que supone. Es en este punto donde reside la grandeza de esta red social, en el poder que ejerce sobre las masas y en su capacidad para trasladar ideas y pensamientos de manera rápida y contundente.

Este trabajo estará centrado en el estudio del impacto y uso que hacen los cuatro principales medios generalistas digitales españoles de las redes sociales, centrándonos en especial en la red social Twitter, por la importancia que ha adquirido en pocos años, dentro de la profesión y trabajo del periodista.

En primer lugar analizaremos la presencia y uso que hacen en las redes sociales, centrándonos en cuántos seguidores tienen; a que personas, entidades, grupos o paginas siguen; así como cuándo empezaron el uso de éstas.

En segundo lugar, escogeremos a los periodistas de estos medios, con más seguidores y analizaremos su actividad, comprendida en el periodo de una semana. Una vez hayamos identificado los principales periodistas o colaboradores de los cuatro medios digitales con más peso en España, comenzaremos presentándolos brevemente. A continuación indicaremos cuantos seguidores tienen, a quienes siguen, el numero de sus tuits, así como la fecha de su incorporación a la red social y por último analizaremos su actividad dentro de esta, durante la tercera semana de enero del 2015 (lunes 12 a domingo 18), en la que día a día examinaremos cuantos tuits realiza, el tema sobre el que tratan, si son de redacción propia o retuits de otros usuarios.

\section{Los medios impresos en la era digital}

En España, el cuarteto de principales medios impresos generalistas lo conforman, los diarios: El País, El Mundo, ABC y La Razón. Con la llegada y popularización de Internet estos cuatro medios de comunicación se vieron obligados a entrar y competir en un medio completamente nuevo, el digital, un nuevo medio que implicaba muchísima más atención que el formato de papel, puesto que este debía actualizarse constantemente, ofreciendo información fresca a sus visitantes, que antiguamente tenían que esperar a la tirada del día siguiente para enterarse de cualquier última noticia. Así mismo estas nuevas plataformas tenían la posibilidad de ofrecer algo más que texto, a este podían acompañarle, archivos de imágenes o archivos de audio y vídeo, lo que suponía el doble trabajo para el periódico (Cebrián, 2104: 69).

Sin embargo estos supieron adaptarse y aunque en un principio fue costoso, con el pasar del tiempo y la digitalización masiva de nuestra sociedad, vieron al fin recompensado su esfuerzo, ya que consiguieron incrementar su influencia ya no sólo so- 
cialmente, sino también geográficamente pudiendo traspasar fronteras y expandirse por el mundo, gracias a ello también empezaron a ofrecer productos comunicativos más elaborados y complejos que las simples noticias escritas. Habiéndose ya establecido en la red, los medios ya digitales tuvieron que enfrentarse a un nuevo problema, el surgimiento de los servicios de red social, que si en un principio supusieron la posibilidad de socializar y hacer amistad en la red, evolucionaron rápidamente para ser una nueva herramienta que permitía la comunicación de masas, capaz de consumir información y también de generarla (Muñoz, 2009: web).

No obstante y al igual que pasara con el boom de Internet, los medios de comunicación supieron responder y ninguno de ellos se ha quedo atrás, se adaptaron a estas y abrieron sus cuentas oficiales, comenzando así la búsqueda y atracción de usuarios en las redes sociales. Sin duda alguna, en muy poco tiempo la herramienta social favorita y más utilizada en este mundo periodístico es Twitter. Cada periódico tiene varias cuentas verificadas dentro de esta red social: una general, otra de deportes, de noticias nacionales, de noticias internacionales, etcétera. Todos ellos buscan de esta manera ganar mayor repercusión, e influencia, algo que sin duda consiguen. Twitter es utilizado como vehículo de comunicación para acceder a la gente, contactar, preguntar, consultar, ser corregido, aclarar dudas... (Marta, 2014: 367). Por ello para los medios de comunicación se han convertido en una herramienta imprescindible, ya que estos tienen el poder de llegar más rápido y a más gente que el diario digital, ya que una persona puede entrar o no a visitar la web de un determinado periódico, pero sin lugar a dudas es más que seguro que tenga una cuenta en alguna red social y pase bastante tiempo en ella (Carrera et al., 2012: 42). Además la aparición de los Smartphone ha supuesto, el empujón final para establecer a las redes sociales como un sólido instrumento de comunicación y de transmisión de información.

\subsection{Análisis de los medios en las redes sociales}

En este apartado investigaremos los cuatro periódicos generalistas seleccionados con más peso en nuestro panorama nacional, para ello primero realizaremos una comparativa mediante dos tablas que nos muestran en primer lugar, la presencia en las tres redes sociales (más destacadas) de estos medios y en el segundo veremos el número de seguidores que estos tienen en las mismas.

Tabla 1. Presencia en las Redes Sociales. Fuente: elaboración propia

\begin{tabular}{|l||c||c||c||}
\hline \multicolumn{1}{|c|}{ MEDIO } & TWITTER & FACEBOOK & YOUTUBE \\
\hline \hline El País & $\mathbf{S I}$ & $\mathbf{S i}$ & $\mathbf{S i}$ \\
\hline \hline El Mundo & $\mathbf{S i}$ & $\mathbf{S i}$ & $\mathbf{N o}$ \\
\hline \hline ABC & $\mathbf{S i}$ & $\mathbf{S i}$ & $\mathbf{S i}$ \\
\hline \hline La Razón & $\mathbf{S i}$ & $\mathbf{S i}$ & $\mathbf{N o}$ \\
\hline
\end{tabular}

Esta primera tabla nos muestra y de paso reafirma de manera clara lo dicho en el punto anterior, sobre la presencia abrumadoramente dominante de los cuatro periódi- 
cos más importantes del país en las redes sociales. Podemos observar que tanto El País, El Mundo, ABC y La Razón están presentes tanto en Facebook como en Twitter, las dos redes sociales más relevantes y populares en el planeta y es que entre las dos cuentan con alrededor de 1.200 millones de usuarios en todo el mundo. Por lo que su presencia es más que obligada ya que de no estarlo supondría un duro golpe a la hora de posicionarse como uno de los medios más influyentes, en tercer lugar hay que matizar que escogimos YouTube como tercera opción frente a otras, debido principalmente en que esta plataforma de vídeos, ha permitido que mucha gente pueda tener sus videoblogs o un canal en el que poder dar su opinión, trasmitir información y entretener. Algo que otras redes descartadas como Instagram, Snapchat... no pueden ofrecer. En la plataforma de vídeos propiedad de Google encontramos que sorprendentemente mientras que El País y $A B C$ cuentan con un canal en el que subir sus vídeos, un medio como es El Mundo, el segundo más leído en el país, no lo tenga, La Razón por otro lado, no teniendo tanto peso como los anteriores no era de extrañar.

Tabla 2. Seguidores en las Redes Sociales. Fuente: elaboración propia

\begin{tabular}{|l||r||r||r||}
\hline \multicolumn{1}{|c||}{ MEDIO } & TWITTER & FACEBOOK & YOUTUBE \\
\hline \hline El País & 3.830 .000 & 1.584 .910 & 5.752 \\
\hline \hline El Mundo & 1.600 .000 & 1.086 .776 & - \\
\hline \hline ABC & 672.000 & 449.081 & 71 \\
\hline \hline La Razón & 139.000 & 145.245 & - \\
\hline \hline
\end{tabular}

La segunda tabla se centra en el número de seguidores que tiene cada medio, en la respectiva red social. Nada mas observar la tabla nos damos cuenta como El Mundo y El País se desmarcan ampliamente de las otras dos publicaciones en Facebook y Twitter, donde ambos tienen en sus respectivas cuentas más de un millón de seguidores. En Twitter, El País consigue ligera ventaja respecto el periódico fundado por el ilustre Pedro J. Ramírez, consiguiendo dos millones más que El Mundo, en cambio en Facebook esta diferencia no es tan clara, ya que aunque El País sigue obteniendo más seguidores su ventaja es apenas de medio millón de usuarios.

$A B C$ y La Razón apenas superan o se quedan en el umbral, del medio millón de seguidores en las dos redes sociales. Mientras que en Facebook y Twitter, $A B C$ se convierte en el tercer medio con más seguidores (449.075 y 672 millones de seguidores), La Razón obtiene apenas 139 mil suscriptores en Twitter y 449.075 mil suscriptores en Facebook, se queda con el cuarto y último puesto. En cuanto a YouTube, El País obtiene una aplastante victoria frente a $A B C$ con sus 5.752 suscriptores, frente a los míseros 71 que tiene el segundo.

\section{Análisis de los principales periodistas sociales en Twitter}

Es innegable que lo que mueve a los medios de comunicación es conseguir lectores, por ello hoy en día, se ha convertido en un requisito de máxima importancia para un periódico digital, el tener un periodista con muchos seguidores en las redes sociales. Una persona que sirva de imagen para la marca de la empresa o grupo editorial al que 
pertenezca el autor, y también para la comunicación. Hay periodistas que superan los 100.000 seguidores en Twitter, lo cual es una muy buena cifra, para una mejor facilidad a la hora de difusión de ideas.

Para analizar la influencia más directa de estos periódicos, hemos elegido a los tres periodistas con más seguidores dentro de la red social Twitter, de cada uno de los cuatro periódicos anteriores, a excepción de La Razón donde su director alcanza el máximo número de seguidores con una cifra insignificante comparado con el resto de los periodistas analizados. Veremos su actividad durante la semana que comprende del lunes 12 al domingo 18 de enero de 2015 y sus diferentes estilos al tuitear.

\subsection{El País}

Los tres periodistas de El País con una mayor actividad y seguidores en Twitter (la red social preferida por los periodistas) son Miguel Ángel Bastenier, Carlos Elordi Cué y Fernando Garea.

\subsubsection{Miguel Ángel Bastenier: @MABastenier}

Es un periodista que no tiene cuenta en Facebook, ni Instagram ni otra red social que no sea Twitter. Como cita su biografía en esta plataforma: "Periodista, articulista y profesor de la Escuela de EL PAÍS, maestro de la Fundación Gabriel García Márquez de Cartagena (Colombia) " acompañado por un enlace que nos dirige directamente a su sección en la web de El País, donde aparecen todos sus artículos.

En enero de 2015, su número total de seguidores en Twitter es de 168 mil, y su cantidad de tuits es de 24,1 mil. Sigue a 748 usuarios, la gran mayoría de ellos son periodistas y medios de comunicación en variedad de idiomas y de diferentes lugares del mundo.

Su actividad durante la semana del lunes 12 de enero al domingo 18 ha sido variada, aunque con repetición en temas tan recientes y controvertidos como ha sido el caso del fanatismo religioso causado por la masacre de Charlie Hebdo y los sucesivos casos ocurridos en Francia. Además de publicar tuits donde facilita el enlace de sus artículos, Bastenier tiene una gran diversidad de temas, muchos tuits son contestaciones a menciones de otros usuarios, hace muchísimos retuits a otras cuentas y, a veces, plantea preguntas para que los followers piensen sobre algunos temas de actualidad. También tuitea enlaces de otros medios de comunicación con información internacional.

Cada día, sin contar retuits, menciones a otras cuentas o enlaces o respuestas a otros usuarios, Bastenier publica entre 10 y 15 tuits. Luego, el número de ese otro tipo de actividad hace triplicar la cantidad de entradas al día. Desde la gala del Balón de Oro de fútbol, que se entrega cada año, pasando por cierta información del continente americano (del que es experto), el tema que más toca con diferencia es el referente a Charlie Hebdo y toda la repercusión que ha tenido. También publica todos los días algún tuit referente al periodismo como profesión: algunos trucos, formas de trabajar, etcétera.

Durante esta semana ha publicado un total de 20 tuits propios con las palabras "Charlie Hebdo"; del sobrecogedor aumento de ventas que ha vivido tras el atentado, de la opinión del Papa, del sector islámico, etc. Sin embargo, su tuit con mayor re- 
percusión no fue referente al caso francés, si no a uno de la profesión del periodista, con un total de 62 retuits y 38 favoritos.

En resumen, la gran actividad de Bastier en Twitter durante la semana analizada, ha dejado un total de 137 tuits y 136 retuits.

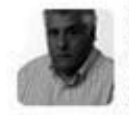

M. A. Bastenier @MABastenier - 17 de ene.

Una filtración periodistica no es una investigación, es un favor que alguien pretende que haya que devolver.

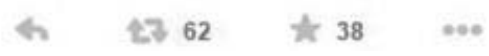

\subsubsection{Carlos E. Cué: @carlosecue}

Carlos Elordi Cué es otro periodista de El País encargado de hacer el seguimiento al Partido Popular. Como dice su biografía de Twitter: "Periodista de EL PAÍS especializado en política, interesado en economía y muchas otras cosas".

Su número de seguidores en enero de 2015 es de 72,4 mil, mientras que sigue a 536 usuarios, la mayor parte son otros periodistas y medios de comunicación de toda las variedades y lugares del planeta. Su número de tuits desde que se registró en esta red social, en octubre de 2009, es 14 mil.

Durante la semana del 12 al 18 de enero, su actividad ha sido la siguiente:

- Lunes: todos sus tuits van relacionados con el nombramiento de Carlos Floriano como jefe de campaña del PP para municipales y autonómicas. No publicó muchos mensajes, un total de cuatro tuits propios más cuatro retuits.

- Martes: este día, sin embargo, apenas hubo actividad en la cuenta de Cué. Solamente un tuit propio, referente a la futura visita del presidente Rajoy a Samarás en Grecia. Aparte de esto, tres retuits de otras cuentas sobre Charlie Hebdo.

- Miércoles: el 14 de enero sí que fue un día de bastante actividad en su cuenta, sobre todo en cantidad de retuits. Fue el día del encuentro entre Rajoy y Samarás en Grecia. Sus cinco tuits propios hablan de la campaña de los dos presidentes contra Podemos y Syriza. Sus 13 retuits son mucho más variados, tocando temas de Cataluña, Hollande, las demandas de paternidad de Juan Carlos I y los ajustes que pide Bruselas a Italia.

- Jueves: poca actividad en el día. Otra vez un solo tuit propio, referente a la portada de un periódico griego, más tres retuits sobre el accionista de New York Times, Carlos Slim y terrorismo en Bélgica.

- Viernes: tres tuits propios sobre miembros del PP y algunos comentarios realizados en rueda de prensa, y otros dos retuits de política nacional.

- Sábado: otro día en el que tan sólo escribe un tuit propio, que dice así: "El PP se define como "absolutamente ajeno" a la trama Gürtel. Al fin llega el comunicado y eso es lo que dice:" con el enlace a tu artículo en El País. Más ocho retuits de noticias de otros compañeros.

- Domingo: el último día de nuestra semana tampoco tiene mucha actividad. Con un tuit propio que enlaza a una noticia no escrita por él y dos retuits referentes a la trama Púnica y los movimientos migratorios en Europa, el 18 de enero es el día con menor actividad twittera de Carlos E. Cué. 
Resulta curioso cómo este periodista, con tan pocas publicaciones propias, puede tener tantos seguidores. En comparación con Bastenier, su actividad diaria es muy pequeña y, aun teniendo menos seguidores que éste, consigue un mayor número de retuits. También cabe destacar que apenas hace menciones o responde a tuits de otros usuarios.

Su tuit más destacado de esta semana ha sido del día 14, con 79 retuits y 38 favoritos.

\subsubsection{Fernando Garea: @Fgarea}

El tercero en la lista de El País es Fernando Garea, que es el corresponsal parlamentario del periódico. Como dice su biografía de Twitter: "Periodista. Corresponsal parlamentario de EL PAÍS".

Su número total de seguidores en enero de 2015 es de 70,4 mil. Él sigue a 874 usuarios, que son medios y periodistas de lugares muy variados. El total de tuits escritos desde que se registrara en Twitter, en octubre de 2009, es de 20,6 mil.

Analizamos su actividad durante la semana:

- Lunes: únicamente tres tuits componen su actividad el 12 de enero. Uno de ellos es la publicación de una noticia suya referente a la Ley Mordaza, y los otros dos a la "injusticia" que fue que el Cholo Simeone no ganara el título al mejor entrenador de 2014.

- Martes: también con un total de tres tuits. Dos suyos y el otro un retuit que menciona una frese dicha por Garea. Los otros dos, enlazando a dos noticias suyas. El único retuit que hace es de Óscar Sánchez Alonso sobre Rato y Bankia.

- Miércoles: el día 14 escribió ciertos mensajes con bastante repercusión. Cuatro tuits en total refiriéndose a relación entre Gobierno y PSOE en dos noticias suyas y un mensaje sarcástico acerca de las palabras de Rajoy. El número de retuits conseguidos supera el centenar en sus dos noticias.

- Jueves: en este día de derbi madrileño (Real Madrid-Atlético) Garea nos deja claro su gusto por el equipo rojiblanco y por Fernando Torres en un par de tuits pero, fútbol aparte, publicó uno que superó los doscientos retuits acerca de un caso surrealista ocurrido en la Comisión de Justicia. Además de esto, hizo dos tuits enlazando a noticias del periódico.

- Viernes: este día también escribió tan solo cuatro tuits, pero todos ellos con mucha repercusión. Empezando por anunciar la muerte del etarra Bolinaga, publica tres enlaces a noticias concernientes a diferentes casos del PP. Una de ellas, referente a la dimisión de Ana Mato, llegó a los 400 retuits.

- Sábado: el 17 de enero sólo publicó un tuit, mencionando un mensaje cholista (fan del Cholo Simeone) de un político vallisoletano.

- Domingo: un solo retuit ocupa su actividad del domingo del periodista Màxim Huerta, sobre unas palabras del líder de Podemos. 
La actividad en Twitter de Fernando Garea no es muy abultada, pero es cierto que cada vez que publica un tuit, la repercusión que tiene en la red es notable. Su media de tuits al día es de tres o cuatro, y los retuits que realiza también son muy escasos. Aparte de esta cuenta en Twitter, Garea tiene un blog dentro de El País llamado "El patio del Congreso".

Su tuit con mayor número de retuits y favoritos de esta semana fue el publicado el día 16 de enero, con un total de 464 retuits y 101 favoritos.

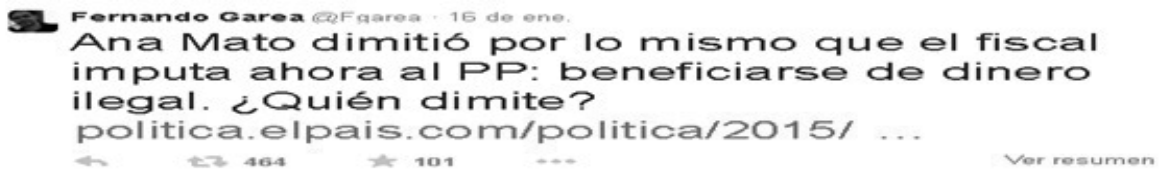

\subsection{El Mundo}

Después de una búsqueda exhaustiva por Twitter, los tres periodistas de El Mundo que cuentan con más seguidores tienen dentro de la red social son: Casimiro García Abadillo (director del periódico), Fernando Lázaro Fernández y Jaime Rodríguez Carrasco.

\subsubsection{Casimiro García Abadillo: @garcia_abadillo}

Casimiro García Abadillo es un periodista, nacido en 1957, licenciado en Periodismo por la Universidad Complutense de Madrid y actual director del diario El Mundo. No cuenta con cuenta en Facebook, lo único que encontramos de él, es una página de interés que enlaza con Wikipedia. Se unió a Twitter en febrero de 2011, su biografía es bastante sencilla y directa: "Periodista y director de EL MUNDO" acorde con su cargo.

A enero de 2015 tiene la cifra de 72.700 seguidores, sigue a 518 personas de entre las cuales la gran mayoría son periodistas que trabajan en su periódico u otro medio, tanto nacional como extranjero, aunque también encontramos algunas cuentas como la de la Casa Real, la embajada americana en Madrid y varios medios de comunicación extranjeros.

En cuanto a su volumen de tuits, es relativamente baja, 8.050, sobre todo para ser director de un periódico, su predecesor Pedro J. Ramírez, le triplica este número. Su actividad durante la tercera semana de Enero (12-18) ha sido:

- Lunes: sin ninguna actividad.

- Martes: durante este día realizo, realizo cuatro tuits y siguió a dos personas nuevas, ambas periodistas, de La Sexta y $C N N$ respectivamente, no hubo un tema destacado. Habló del caso Puyol, la portada en honor al atentado del Charlie Hebdo. Todos los tuits fueron enlaces a artículos más interesantes del día en su periódico, el que más atención generó, es el relacionado con la unión nacional ¿Podremos alguna vez en España cantar un mismo himno unidos?.

- Miércoles: realizo cinco tuits, cuatro de ellos nuevamente enlaces, a los artículos destacados de el día en El Mundo, sin centrarse en ningún tema en general (Charlie Hebdo, elecciones ERC...) el único tuit que no fue enlace, era la despedida del periodista fallecido José Luis Alvite. 
- Jueves: sin ninguna actividad.

- Viernes: simplemente hubo dos tuits, ambos enlaces al periódico y sin ningún tema en común, el más destacado, una crónica sobre Manuel Jabois, que abandona la redacción de El Mundo ante el fichaje de El País.

- Sábado: sin ninguna actividad.

- Domingo: cuatro tuits y siguiendo su estela, todos enlaces de artículos, que no tienen tema común, el más destacado, uno sobre el Charlie Hebdo.

El tuit más destacado de la semana con 496 retuits y 137 favoritos es el único que redacto sin ser un enlace, y que se despedía del redactor Jabois que abandonaba el periódico.

\subsubsection{Fernando Lázaro Fernández: @lazaroelmundo}

Es un periodista de El Mundo, encargado de seguridad y terrorismo, al igual que el director no pose cuenta de Facebook, así mismo, su biografía es igual de sobria y seca que el anterior "periodista de EL MUNDO. Seguridad y terrorismo". Se registró en Twitter en marzo de 2011, desde entonces y hasta la fecha ha conseguido 10,4 millones de seguidores y sigue a 2.838 personas, casi el cuádruple que su director, la gran mayoría también periodistas y compañeros de profesión, así como personajes de interés, también sigue a otros medios de comunicación. Su actividad durante la semana de análisis fue:

- Lunes: siguió a dos cuentas nuevas, una periodista y una academia de policía. En cuanto a publicaciones, sólo hubo un tuit, que resultó ser un enlace a un artículo del periódico.

- Martes: fue un día intensó de actividad, realizo ocho tuits, cuatro de ellos eran enlaces a artículos, mientras que los otros cuatro eran contestaciones y charlas con otros usuarios, el tema del día aparte de la seguridad fue el aniversario de la fundación de la Policía.

- Miércoles: al igual que el martes bastante intenso, hubo 13 tuits, nueve de ellos enlaces, sin embargo los otros tres fueron un comentario sobre la lluvia en Madrid y otro sobre la posible remontada del Madrid en el partido que se jugaba, hizo además 3 retuits, un video, una imagen en la radio en a que sale él y un comentario que está relacionado con el tema del día, los yihadistas.

- Jueves: relaja la actividad y sólo publica tres tuits, una como no podía fallar es un enlace y las otras dos se dividen en un comentario de la izquierda abertzale y el ultimo comentando el programa de Radio Marca en el que colaboró.

- Viernes: se hacen tres tuits y dos retuits. La única entrada redactada que no es un enlace o respuesta a otro usuario habla de Podemos y su posible relación con el partido Izquierda Anticapitalista, el último tema que trata es la muerte de Bolinga.

- Sábado: se producen dos tuits con enlaces a artículos, y dos comentarios uno sobre el País Vasco y Bildu, y el otro sobre Podemos.

- Domingo: realiza cinco tuits y dos retuits. De todos los tuits, los que más seguimiento tuvieron fueron el enlace en el que alaba el relato de Ana Iribar sobre el asesinato de su marido Gregorio Ordoñez por ETA en el diario. Y el tuit más 
destacado de la semana con 111 retuits y 28 favoritos fue el único que redacto sin ser un enlace sobre "Bildu y Podemos convocan conjuntamente a un acto mañana en Navarra a favor de los abogados de ETA".

\subsubsection{Jaime Rodríguez Carrasco: @jaimeELMUNDO}

El último de los tres periodistas con más seguidores de El Mundo, se dedica a los deportes, al igual que los anteriores carece de cuenta en Facebook $u$ otra red social que no sea Twitter, a la cual se unió en marzo de 2010, su biografía no es más que "periodista EL MUNDO" siguiendo con la estela de sobriedad sus compañeros.

En cuanto a sus seguidores aquí se produce un bajón con respecto a os otros dos, ya que hasta la fecha sus seguidores apenas son 4420 personas, aunque eso si supera en gente a la que sigue a sus compañeros 834 personas, algunos son periodistas pero también hay personas relacionadas con el mundo del deporte, así como otras cuentas que está claro que son de interés solo para el periodista, su actividad esa semana fue:

- Lunes: el día que más actividad se va a producir y que estará relacionada con la gala del balón de oro, dos serán imágenes del premio y de los votos que saca cada jugador y el resto de tuits serán comentarios sobre los acontecimientos de la gala.

- Martes: sin actividad.

- Miércoles: sin actividad.

- Jueves: se producen cuatro tuits, uno con imagen que hace referencia a la llegada del Madrid al estadio del Calderón, el tema de las cuatros tuits va sobre el partido Madrid-Atlético.

- Viernes: un tuit, es un enlace a un artículo en la plataforma digital Orbyt.

- Sábado: sin actividad.

- Domingo: sólo un tuit que hace relación a Simeone.

Su tuit más destacado en la semana el anuncio el día 12 de la victoria de Cristiano Ronaldo del Balón de Oro.

\section{3. $A B C$}

Los tres periodistas de $A B C$ que más seguidores tienen en esta red social son, por orden descendente, Carlos Herrera, Hermann Tertsch y Bieito Rubido.

\subsubsection{Carlos Herrera Crusset: @carlosherreracr}

Carlos Herrera es un periodista almeriense nacido en 1956. Más conocido por su voz penetrante en el programa de radio "Herrera en la Onda" de Onda Cero. Herrera también es pagado por $A B C$ como columnista.

Su cantidad total de seguidores en Twitter es de 154 mil personas, aunque él solo sigue solamente a 50 usuarios y tiene publicados 877 tuits desde que se registrara en noviembre de 2011. A juzgar por la incorporación de otros periodistas a este mundo social, Herrera ha tardado un par de años en iniciarse en Twitter.

$\mathrm{Su}$ actividad durante esta semana es escasísima, con un total de cuatro tuits, tres de ellos publicados el 13 de enero y el otro el día 16. Además, su contenido es de expe- 
riencias que ha vivido esos días, nada tienen que ver con periodismo o casos de actualidad.

- El martes, sus tres tuits son de imágenes relacionadas con la Semana Santa sevillana.

- El viernes un sólo tuit de una fotografía con una amiga de Melilla.

Resulta extraño que un periodista, aunque sea tan reconocido nacionalmente, tenga tal cantidad de seguidores en Twitter si únicamente publica mensajes individuales, familiares o de cualquier tipo sin tener nada que ver con los medios. Herrera no lo usa como una herramienta de trabajo, donde enlaza sus columnas u opina de temas de actualidad, sino que lo emplea como una persona normal, sin interés periodístico.

\subsubsection{Hermann Tertsch:@hermanntertsch}

El polémico Hermann Tertsch también deja sus ideas plasmadas en las redes sociales. Desde mayo de 2007 es analista político, crítico, entrevistador y columnista de $A B C$. En Twitter tiene 67,4 mil seguidores, sigue a 2 mil usuarios y tiene un total de 93,3 mil desde que se uniera en febrero de 2011. Una cantidad de tuits enorme.

Su biografía en la red dice así: "Periodista. ABC. siempre razonablemente estupefacto". A diferencia de Carlos Herrera, sus publicaciones sí que tienen que ver con el ámbito periodístico. Su actividad durante esta semana ha sido la siguiente:

- Lunes: unos 30 tuits propios, contando respuestas y menciones a otros, con una cantidad de retuits mucho mayor. Entre ellos enlaza a diferentes webs con sus columnas, da su opinión acerca de temas candentes pero, sobre todo, menciona palabras y mensajes del líder de Podemos, Pablo Iglesias, para utilizarlos en su contra.

- Martes: otro día igual que el anterior. El que mayor número de retuits tuvo fue una noticia de $A B C$ sobre la muerte de trece personas en un hospital de Caracas por falta de medicamentos. También algunos casos candentes de Alemania, como el de Pegida y los anti islamistas.

- Miércoles: día con igual variedad, con comentarios acerca de Maduro, algunos etarras, Podemos... pero el más influyente fue uno con casi 200 retuits, que dice así: "Cintora, Wyoming, Escolar, Ferreras, Pastor... La secta desfilando con orejas de burro a pedir disculpas por mentir con la dueña de Excaliburl".

- Jueves: una cantidad de tuits y retuits ingente, de todos los temas. Acerca de la visita de Maduro a Moscú, enlaces a su columna, las palabras del Papa, etc. Todas ellas con un comentario que deja clara su opinión acerca del tema.

- Viernes: "La resbaladiza senda de la ofensa" es el título que tiene su columna este 16 de enero. Lo enlaza muchas veces y hace innumerables retuits de gente que recomienda su columna, que trata de las palabras del Papa. También opina sobre Bolinaga y algunos etarras.

- Sábado: este día se centra en hacer mención a lo malo del nazismo y del comunismo, enseñando imágenes de la Unión Soviética y el régimen nazi. Más retuits sobre sus columnas "La resbaladiza senda de la ofensa" y "El infierno de Hölderlin", que trata sobre los peligros del comunismo. Además, sigue con el tema de Bolinaga y mencionando a Pablo Iglesias. 
- Domingo: el último día de la semana no está exento de actividad. Tertsch menciona la entrevista de $A B C$ a Albert Rivera, la comparecencia de Morenés, hace una dura crítica contra la enfermera del Ébola Teresa Romero, así como contra Bolinaga y Pablo Iglesias, Monedero y su partido.

Su actividad es intensísima con una media de cincuenta tuits diarios, utilizando un lenguaje muy ácido para criticar casi siempre a los mismos, como ya se ha visto en el día a día.

Su tuit más influyente de la semana fue uno del domingo 18, con 274 retuits y 146 favoritos.

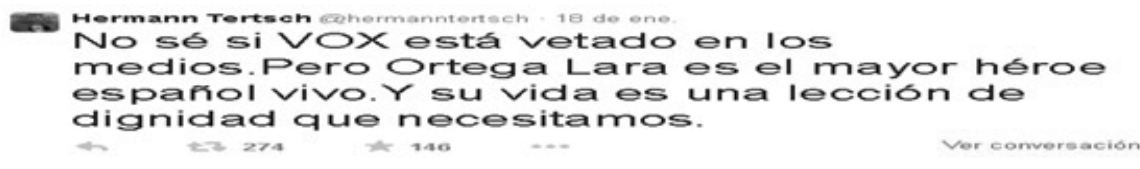

\subsubsection{Bieito Rubido: @bieitorubido}

Es un periodista gallego director de $A B C$ desde 2010. Su biografía en Twitter dice así:

"Toda mi vida he querido ser periodista. No recuerdo otra vocación. Es un privilegio dirigir ABC, innovador en su nacimiento y que aspira a seguir siéndolo".

A pesar de ser el director del diario, su número de seguidores no es de los más altos, ya que tiene 14,7 mil y sigue a 492 usuarios. Su incorporación a la red se produjo en abril de 2011 y desde entonces ha publicado un total de 6,6 mil tuits. Su actividad de la semana es:

- Lunes: el primer día de la semana solamente ha publicado un tuit, que enlaza a la portada del periódico, referente a París y el movimiento contra el terrorismo.

- Martes: el día 13 publica dos tuits, ambos enlazando la portada de $\mathrm{ABC}$, refiriéndose a la guerra contra la yihad.

- Miércoles: este día no hubo actividad en su TimeLine.

- Jueves: dos tuits acerca de un intento de atentado en Bruselas y otro de la mala gestión, según el diario, de Artur Mas con Cataluña. También enlaza la portada.

- Viernes: enlaza la portada, en la que vuelve a mencionar el combate de Europa contra los yihadistas.

- Sábado: el día con más actividad de la semana. Hace varios retuits sobre: la NASA, una conferencia en directo del Papa y la sociedad española, aparte de enlazar la portada de $\mathrm{ABC}$.

- Domingo: sin actividad.

El director de $\mathrm{ABC}$ se centra en publicar las portadas de su diario en su cuenta de Twitter. No hace casi retuits y no tiene menciones o respuestas a otras cuentas. Sus tuits apenas llegan a la veintena, así que no es reseñable ninguno de ellos.

\subsection{La Razón}

En el caso de La Razón solo analizamos a un periodistas, Francisco Marhuenda director del periódico puesto que solo él tiene un número considerable de seguidores, el 
resto de los periodistas pertenecientes a la redacción, apenas ronda los 550 a 1000 seguidores y sus tuits, van más a lo personal que a lo periodístico y la única Carmen Morodo Vioque, que supera los cinco mil seguidores hace meses que no saca un nuevo tuit, en concreto desde julio de 2012.

\subsubsection{Francisco Marhuenda: @pacomarhuenda}

"Director del diario La Razón", así es como se presenta el periodista en su cuenta, se unió a Twitter en mayo de 2011, un poco tarde teniendo en cuenta el boom de las redes sociales, a día de hoy tiene 72.500 seguidores y sin embargo sólo sigue a 39 personas, periodistas y amigos de él. Su actividad durante la semana de análisis fue breve:

- Lunes: se producen dos tuits, uno es un enlace a un artículo, y el segundo un tuit que explica donde ira ese día, a La Sexta al programa "Al Rojo Vivo".

- Martes: un único tuit en el que informa que ese día ira a la Cadena Cope al programa "La mañana".

- Miércoles: sólo dos tuits, una informando de su vuelta a la Cadena Cope pero esta vez al programa "La Linterna" y el último ofreciendo la portada del día siguiente de la edición de papel.

- Jueves: en sus tres tuits, de nuevo deja la portada de el día siguiente, e informa que ese día ira a dos programas "Es la mañana de Federico" en esRadio y por la noche a "El Cascabel" en $13 T V$.

- Viernes y sábado: en ambos días deja exclusivamente el tuit con la portada del periódico y el sábado vuelve a informar que estará en el debate de La Sexta "laSexta Noche".

- Domingo: vuelve a dejar la portada de La Razón.

Como podemos observar, el director de este medio, usa más bien Twitter como anuncio de todos los programas en los que va a participar, sin hacer uso del contenido periodístico que hacen en este microblogging los profesionales de los otros medios analizados.

\section{Conclusiones}

La red social que triunfa entre los periodistas elegidos es Twitter, porque es la manera más directa de llegar a la sociedad. Los periodistas escriben a diario y difunden las informaciones que realizan en sus periódicos a través en un tuit que enlaza esa noticia a la web. Es cierto que destacan algunos casos en los que la actividad es muy elevada -Bastenier y Tertsch-. Como excepción encontramos que dos de los directores de los medios analizados $A B C$ y La Razón tienen un nivel de actividad bajo, no utilizan las redes sociales con la frecuencia que esperábamos obtener antes de realizar el estudio.

Los profesionales seleccionados prefieren utilizar Twitter de manera profesional, como un arma divulgativa de su trabajo en redacción. De manera individual existen excepciones, pero no se suelen dar casos en los que el periodista haga uso sólo personal de su perfil, salvo Carlos Herrera.

Todos los periodistas seleccionados siguen en sus perfiles de Twitter a periodistas tanto compañeros de redacción como de otros medios. Esta red facilita y mantiene al corriente de las actividades de los compañeros de profesión. 
La diferencia entre los medios El País y $A B C$ es bastante notable. El número de seguidores que tiene el primero supera con creces al segundo. Hay un dato reseñable: $E l$ País se unió a la red social Twitter en -agosto de 2007- casi dos años antes que ABC en -febrero de 2019-, lo que supone una ventaja muy grande a la hora de conectar con los usuarios.

La popularidad entre los periodistas, es otra de las diferencias. El País cuenta con gran cantidad de profesionales que supera los 10 mil seguidores, periodistas que son muy retuiteados y su opinión se tiene en cuenta entre los usuarios. Además hay gran variedad: deportivos, de guerra, fotógrafos... $A B C$ no cuenta con esos periodistas con tan popularidad y tanta fuerza en las redes sociales, por lo menos no tanto comparado con el resto, y es un hándicap muy grande que tiene que superar. La Razón tampoco los tiene, el único que cuenta con miles de seguidores en la red social es su director, y sus tuits tampoco son tantos, ni tan variados como la de los otros periodistas.

La Razón claramente desaprovecha las redes sociales, puesto que tampoco tiene canal de YouTube y su Facebook no destaca mucho frente a los otros tres medios, caso contrario es El Mundo este sí que aprovecha las redes sociales y si bien El País sigue superándole, si vemos los análisis de las semanas de los periodistas de ambos medios veremos que son infinitamente más largas que las de $A B C$ y La Razón, con esto queda claro que en nuestro país hay solo dos medios que se disputan el liderazgo e influencia, mientras que el resto aun con un buen número de seguidores, no parece haber encontrado la manera de explotar el uso de las redes sociales y llegar a captar más usuarios.

\section{Referencias bibliográficas}

CAMPOS FREIRE, Francisco (2008): "Las redes sociales trastocan los modelos de los medios de comunicación tradicionales". Revista Latina de Comunicación Social, núm. 63, pp. 287-293. La Laguna (Tenerife): Universidad de La Laguna: http://www.ull.es/publicaciones/latina/2008/23_34_Santiago/Francisco_Campos.html [Consulta: 9 de enero de 2015].

CARRERA ÁLVAREZ, Pilar et al. (2012): "Journalism and Social Media: How Spanish Journalists are Using Twitter". Estudios sobre el Mensaje Periodístico, vol. 18, núm. 1, pp. 31-53, doi: http://dx.doi.org/10.5209/rev_eSMP.2012.v18.n1.39353, http://revistas.ucm.es/index.php/ ESMP/article/viewFile/39353/37900. Madrid, Servicio de Publicaciones de la Universidad Complutense.

GARCÍA DE TORRES, Elvira. et al. (2011): "El uso de Twitter y Facebook por los medios iberoamericanos". El Profesional de la Información, noviembre-diciembre, vol. 20, núm. 6, pp. 611-620: http://www.labcom.ubi.pt/publicacoes/201306302226garc a_et_al_2011.el_profesional_de_la_info.pdf [Consulta: 9 de enero de 2015]

FLORES VIVAR, Jesús Miguel (Dir., 2011): Reinventar el Periodismo y los Medios. Madrid, Fragua.

LAJAS PORTILLO; Jacinto (2013): "Informe de Oriella sobre periodismo digital: crece el uso de Twitter entre los periodistas". periodismocuidadano.com: 
http:/www.periodismociudadano.com/2013/06/18/informe-de-oriella-sobre-periodismo-digital-crece-el-uso-de-twitter-entre-los-periodistas/ [Consulta: 2 de enero de 2015].

MARTA LAZO, Carmen y GARCÍA IDIAKEZ, Mikel (2014): "El uso profesional de la red social Twitter en la redacción del diario español El País". Palabra Clave, vol. 17, núm. 2, pp. 353-377: http://palabraclave.unisabana.edu.co/index.php/palabraclave/article/view/3341/3442 [Consulta: 9 de enero de 2015].

MUÑOZ FERNÁNDEZ, Juan Andrés (2009): "10 usos periodísticos de Twitter". Allendegui anacrónicas electrónicas: http://gentedigital.es/comunidad/ allendegui/ 2009/11/18/10-usos-periodisticos-de-twitter [Consulta: 11 de enero de 2015]

REQUEJO ALEMÁN, José Luis y HERRERA DAMAS, Susana. (2011): "Difundir información, principal uso de los diarios generalistas españoles en Twitter". Textual \& Visual Media, $\mathrm{n}^{\circ}$ 4, pp. 149-182: http://textualvisualmedia.com/index.php /es/home-es/9-articulos-publicados/67-diarios-generalistas-espanoles-en-twitter [Consulta: 16 de enero de 2015].

SALGADO, SANTAMARÍA, Carmen y ZAMARRA LÓPEZ, Ma Mercedes (2014): "Sinergias periodísticas en las redes sociales, los medios audiovisuales y la prensa digital", en CEBRIÁN HERREROS, Mariano (Dir.): Innovaciones Periodísticas en las Redes Sociales. Madrid, Servicio de Publicaciones Universidad Complutense de Madrid, $2^{\mathrm{a}}$ edición, pp. 67-106.

ZAMARRA LÓPEZ, Ma Mercedes (2010): "El uso del audio y el vídeo en los ciberperiódicos", en CEBRIÁN HERREROS, Mariano (Dir.): Desarrollos del periodismo en Internet. Zamora, Comunicación Social, pp. 65-79.

ZAMARRA LÓPEZ, Ma Mercedes (2013): "Procedencia y Fuentes de las Redes Sociales" en FLORES VIVAR, Jesús Miguel (Coord.): Contenidos y Servicios Periodísticos en las Redes Sociales. Madrid, Fragua, pp. 139-174. 